\title{
'A Very Flexible Medium': The Ministry of Information and Animated Propaganda Films on the Home Front
}

\author{
Hollie Price
}

Filling the Gap (1942), the first of Halas and Batchelor's films released for the British Ministry of Information (MoI), promoted digging for victory and growing vegetables in all available gardens and allotments. Documentary News Letter - an in-house journal for the documentary movement that closely followed the work of the MoI's Films Division throughout the war - approved of Filling the Gap's 'pleasing' combination of animated diagrams and cartoons, concluding that it 'will probably command more attention in the cinema than most'. ${ }^{1}$ The review also indicates 'an unpleasant change of style at the end in the drawing of the gathering of vegetables', suggesting that this 'smacks of advertisements for Heinz 57 varieties'. In other words, the closing image reinforcing the film's official message belonged to the visual language of commercial advertising, rather than the more subtle, indirect form of public relations that the documentary movement championed. Drawing on a range of archival evidence of the Mol's work, this chapter explores and expands on the claim that Filling the Gap's ending 'smacks of advertisements' by highlighting the burgeoning relationship between animated propaganda films and practices in film advertising and public relations in this period. ${ }^{3}$ Through an examination of the Films Division's programme for film propaganda, its distribution schemes and the films themselves, I demonstrate how the MoI's use of animation developed alongside different forms of animated advertising and that its flexible use is indicative of the intersecting functions of MoI films as propaganda, publicity and education in wartime Britain.

\section{The MoI Films Division}


In January 1940, Kenneth Clark - the newly appointed head of the Films Division at the MoI - circulated a memorandum that presented some ideas on the uses of film for propaganda. Though he was not a film specialist, he suggested that animated cartoons could be 'a very flexible medium of propaganda', which would be particularly useful for showing 'What Britain is fighting for'. ${ }^{4}$ Drawing on Disney for inspiration, Clark emphasised that animated cartoons 'have the advantage that ideas can be inserted under cover of absurdity', detailing how cartoons 'can present (as in Mickey Mouse) a system of ethics in which independence and individuality are always successful, bullies are made fools of, the weak can check the strong with impunity, etc' ${ }^{5}$ For Clark, the value of animated cartoons was that entertaining narratives could camouflage propaganda messages and he optimistically proposed that he knew of 'several artists in England who can do [animated cartoons] really well' 6

Clark's tenure as head of the Films Division was short-lived (he was promoted within the Ministry in April 1940) but he had 'created a healthy atmosphere which prompted filmmakers to approach the division' and his idea of animation as a 'flexible medium of propaganda' was taken up in the work of the Division's final head, Jack Beddington. ${ }^{7}$ During the interwar years, Beddington was the General Manager and Director of Publicity at ShellMex and BP, where he built a reputation as an advertising man par excellence. He was responsible for Shell's enlightened policy on publicity, characterised by an understanding of the expressive potentialof British art and film in advertising. On his appointment, Advertisers' Weekly announced:

Shell-Mex have always been classed [...] as one of the pioneers of a high standard of commercial advertising and Mr. Beddington has been largely responsible for their enlightened policy. He has had experience of propaganda film work through his connection with the Shell-Mex film unit, who have produced a number of excellent publicity films. ${ }^{8}$ 
Under Beddington, the MoI Films Division built up its networks for film distribution. This included a scheme of short films and trailers shown by theatrical exhibitors for free, and its non-theatrical distribution scheme whereby MoI films, as well as documentaries and instructional films acquired from other ministries and studios, were shown in village halls, social clubs and factories using a fleet of mobile film units, projectors and a film lending service based at the Central Film Library. ${ }^{9}$ In the early 1940s, these avenues for distributing propaganda films on the home front offered opportunities for animators also working on films for the purposes of commercial advertising and public relations to make films for the Ministry.

Some of the most prolific animators commissioned to make MoI films were Halas and Batchelor, and Francis Rodker at the Shell Film Unit (SFU). John Halas and Joy Batchelor made approximately 70 cartoon films and trailers for a variety of wartime campaigns and also short films for commercial sponsors including Kellogg's, Lux and Rinso. Francis Rodker's diagrammatic sequences were a key feature of numerous MoI documentaries and instructional films made by the SFU, building on his interwar work on educational films made as publicity for Shell. As the following sections on Halas and Batchelor's drawn animations and Rodker's diagrammatic sequences explore, the MoI's animated films encompassed both the entertaining Disney-influenced narratives that Clark had envisaged and more directly didactic animated diagrams encouraged by the documentary movement. According to several accounts, Beddington cultivated a spirit of experimentation and freedom for filmmakers during this period and, through the Division's growing film distribution networks, the propaganda work undertaken by these studios offered opportunities for their different styles of animation to develop and flourish. ${ }^{10}$ 


\section{Halas and Batchelor}

In 1940, the MoI introduced a series of five-minute films shown in cinemas that would 'help people to remember government messages by putting them in dramatic form'. ${ }^{11}$ Shortly following the introduction of this series, documentary filmmaker Paul Rotha wrote to Sidney Bernstein, the Ministry's resident specialist in commercial film distribution, detailing some ideas and drawing connections between the Ministry's work and advertising:

The 5-minute film is not new. Some of the very best examples of elementary film technique - particularly as regards timing and cutting values - often appears in what are commercially called Trailers [...] the new series of M. of I. 5-minute films offers remarkable chances for similar experiment. ${ }^{12}$

In 1942, the MoI replaced the five-minute films with longer 15-minute films released monthly that allowed for more information to be relayed to cinema audiences, accompanied by trailers - with the same aim of conveying official information in a 'dramatic form' albeit in a tighter timeframe. In the early years of the war, Halas and Batchelor were ideally placed to contribute to these short film schemes. John Halas had previous experience of making animated commercial films and the Halas and Batchelor studio was formed under the banner of the J. Walter Thompson (JWT) advertising agency to continue this work, aided by ideas and scripting from JWT writer Alexander Mackendrick - who had scripted and storyboarded a successful series of cinema advertisements for Horlicks (animated by George Pal, these are discussed further by Mette Peters in chapter 2). Paul Wells emphasises how Halas and Batchelor usefully 'deployed some of the strategies they used in the advertising films they made for the J. Walter Thompson agency' in their MoI films: using entertainment first and mention of the advertised product second. ${ }^{13}$

In two commercials for Lux soap, Carnival in the Clothes Cupboard (1941) and Fable of the Fabrics (1942), Halas and Batchelor experimented with just such techniques aimed at 
'building up the goodwill of the audience through entertainment'. ${ }^{14}$ Both films were fairytale stories set in the mundane, domestic settings of a clothes cupboard and laundry basket: they each focus on a group of characters from the designs and patterns on various garments coming to life, a narrative showing their magical renewal by soap flakes, and a final reveal of the Lux product as the 'pay off to the story climax'. ${ }^{15}$ Carnival in the Clothes Cupboard features a 'dingy and drab' clown who, unpopular with the other characters in the cupboard, attempts to drown himself before being happily transformed by Lux flakes. In Fable of the Fabrics, a cupid from the embroidered corner of a handkerchief stands up to eerie figure 'Old Father Time', using Lux flakes to preserve the other characters' youth and vibrancy. In both productions, recognisable elements from Disney animations - using characters' personalities to provoke 'pathos as well as humour' and semi-magical settings - imbue ordinary, domestic landscapes with this sense of possibility, simultaneously entertaining potential customers and endowing Lux with powers of transformation. ${ }^{16}$

Some of Halas and Batchelor's MoI trailers took a similar tack, depicting wartime domestic transformations in a fairytale style. In From Rags to Stitches (1944), Cinderagella, a rag forlornly mopping the floor in a drab interior is transformed into a nurse's uniform by a trip to the salvage factory with a 'Fairy Rag Bag' - an informative fairy godmother in the form of an anthropomorphic cloth bag. The story is resolved with a trip to the 'War Service Rag Time Ball' and the message: 'when sorting salvage, don't forget the rag bag'. In Mrs Sew and Sew (1944), a resourceful housewife - the face of the Board of Trade's 'Make Do and Mend' campaign - has a magical touch that makes the different components of her sewing kit come to life and get to work on making new clothes out of old. Rather than revealing a product at the end of the film as the reason for the aesthetic renewal as in the Lux films, the 'Fairy Rag Bag' and the resourceful 'Mrs Sew and Sew' drive the narrative and make contributions to 
the war effort seem more appealing (and quasi magical). ${ }^{17}$ In doing so, they aligned alterations to everyday life demanded of audiences with optimistic possibilities of transformation in the language of advertising. By adapting the techniques with which they presented commercial products, these films offered entertaining narratives that would lightheartedly inform audiences of the ways that they could be involved in the war effort.

Another tale of renewal, Halas and Batchelor's five-minute film Dustbin Parade (1942) focuses on a group of anthropomorphised household objects - a spinning top, a bone, a tin can and an empty toothpaste tube - thrown out onto the street and intent on making use of themselves. Made to encourage audiences to recycle household waste in aid of munitions production, it tracks the items' journey: from receiving advice from a nearby fencepost, signing themselves up at the local 'recruitment centre' (recycling boxes outside a front door) to their eventual, communal metamorphosis into an artillery shell. It uses the same idea of enlivening a mundane domestic task by creating the objects to be recycled as distinctive characters and emphasising their transformation. Described by Wells as a film in which 'optimism is allied with efficiency as "Disney" meets "Documentary", this tale of transformation has a realist edge. ${ }^{18}$ Rather than a magical, immediate metamorphosis, Dustbin Parade displays the mechanics of the objects' change into munitions. In factory scenes, the objects are transferred onto a conveyer belt: the paper-characters are compressed cartridges, rubber hot water bottles clamped into tyres and bones into uniforms, and - in perhaps the most visually striking act of self-sacrifice - a row of tin cans dives into the hot liquid in a melting pot, which is poured out into shell moulds. For Wells, the cartoon also 'softens the effect that a necessary "transformation" might have' and 'the sacrifice is one of "change" and not potential endangerment or death'. ${ }^{19}$ Employed to soften the potential threat of the war effort, Halas and Batchelor's use of commercial tropes sold the everyday, exigent 
and dangerous wartime activities in the form of lively, visually arresting cartoon transfigurations.

In 1942, a Mass-Observation report on the reception of the Ministry's five-minute films in cinemas highlighted the important (and difficult) balance between propaganda and entertainment, suggesting that such official films were 'liable to be resented or rejected if they are too much propaganda, and loved but ignored as propaganda if they are too much entertainment' ${ }^{20}$ Halas and Batchelor's films had to tread a fine line between entertainment and information in order to avoid derision and to communicate propaganda messages effectively. The transformation-narratives developed in their advertising work offered a way to do this, using an entertaining format but incorporating a more didactic function in various different ways. For instance, these included cartoon characters offering instructions or advice, such as an outraged talking bin who details how to recycle scrap materials in Model Sorter (1943); a dancing wireless advising animate fuel-using domestic appliances in Cold Comfort (1944); and a cartoon incarnation of popular gardening expert C.H. Middleton who, in the company of a thankful vegetable, explains the importance of the compost heap as a 'plant canteen' in Compost Heaps (1943). As in Dustbin Parade, these characters and narratives illuminate and explain ideas, demonstrating what John Halas describes as animation's 'penetrative' potential for unveiling hidden processes. ${ }^{21}$ For example, in Compost Heaps, Middleton's suggestion 'suppose we get down to the root of the matter' is followed by a combination of pictorial illustrations of a plant, its roots and a compost heap with comic, character-driven animations to symbolise the work of producing nutrients. Revealing this process, the compost heap illustration fades to an x-ray-style image of its interior, where a series of kinetic, anthropomorphised figures work on assembly lines, one of them peddling a cart labelled 'delicious nitrogen potash phosphates' under the earth to deliver to hungry roots. 
Filling the Gap also embodies the combination of the "transforming, penetrating and symbolising powers' attributed by Halas and Batchelor to animation. ${ }^{22}$ Commissioned by the Ministry of Agriculture, the film uses cartoon characters and diagrams to encourage audiences to use all available land to grow vegetables in the face of diminishing levels of imported food. Depicted in a more simple, diagrammatic style, its central character is a silent line-drawn figure, which is used to symbolise the food intake of the national population: the figure's chewing mouth expands into a funnel shape and the rest of its body into the base of a vessel with three empty compartments, accompanied by graphic symbols for vegetables, milk and other foods such as meat and grains - a sack, a bottle and a box - to represent the nation's food supply needs. As a result of the central character's gardening efforts, a series of anthropomorphised vegetables - in a closer style to the personality-animations in Dustbin Parade and others - are shown joyously springing from branches and bouncing from the soil, before they march together with the central figure and are diagrammatically shown filling the gaps left by reducing imports (Figures). Although Documentary News Letter had qualms about this ending and its proximity to commercial advertisements, it conceded that 'animated diagram and cartoon meet in this film on common ground'. ${ }^{23}$ The review suggests that 'by adopting the cartoon's flexibility and some hint of its inconsequent gaiety in their diagram sequences, and by retaining something of the diagram's essential simplicity in their pure cartoon sequences, the makers have achieved a lively and entertaining film'. ${ }^{24}$ Through adapting and developing the tropes of transformation, escapism and sympathetic characters that they were simultaneously using in their commercial work, Halas and Batchelor maintained a focus on conveying information in an entertaining way. Filling the Gap, though, incorporates a more didactic approach and a diagrammatic style later developed in their sponsored films in the immediate postwar period. For the MoI, such animated diagrams 
represented a useful mode of propaganda and this educational function of the animation medium was cultivated, in a different style, in Shell Film Unit documentaries and instructional films.

\section{<FIGURES X 2 “FILLING THE GAP (1942)” ABOUT HERE>}

\section{Francis Rodker and the Shell Film Unit}

Based at the SFU from the 1930s, Francis Rodker was a technical animation specialist whose diagrams appeared in the majority of Shell's wartime output. His wartime diagrammatic sequences were characterised by an austere, realist style, emphasising their straightforward intent as part of the MoI's film propaganda. For instance, Ack-Ack (1941) - a five-minute film sponsored by the War Office to stress how British forces were hitting back against bombing - explains the work of a group of anti-aircraft gunners. It features live-action sequences that capture the nightly activities of their station in an observational style including manning the guns, plotting courses and recreational time, as well as a simple, graphic diagram to explain the exact nature of their work. The voiceover commentary ostensibly provided by one of the gunners themselves - evokes a direct, down-to-earth approach, which explains how the trajectory of the anti-aircraft guns is calculated. With the instruction to 'look at this diagram', a scene fades to an illustration of a German plane annotated with white dotted lines to show both its trajectory and that of the shell fired by the gunners. The sequence is characterised by a sombre visual style: its grey sky background evokes the realist depiction of the station in the film's other scenes and its simple style of white lines (evocative of chalk ones) denotes its didactic function. 
In the 1930s, the SFU specialised in documentary films exploring different technological and scientific themes, which were made as a form of indirect, prestige publicity for the company and which began with a programme of educational films recommended by John Grierson. These early films included Power Unit (1934), which explains the principles of the internal combustion engine illustrated using animated diagrams and model work, and Springs (1937), which used animated diagrams to show the working parts of a car. Any branding was kept discreet: consultant producer Arthur Elton established that 'Shell films were in no way to be classed as advertising films. There was to be no heavy handed waving of the product or the Company name'. ${ }^{25}$ The aim of the films were that they would be used within the company 'to improve the efficiency of the Shell organisation by creating a greater knowledge of the products marketed and of the organisation'; and outside 'to improve the demand for Shell products' and, through the provision of an educational service, 'to create general goodwill' ${ }^{26}$ Having trained as an engineering draughtsman at Shell with a self-confessed 'flair for fine art', Rodker's factual animations played a significant role in illustrating and explaining technical processes and mechanisms. ${ }^{27}$ With the outbreak of the war and the government sponsorship of SFU productions, Rodker's experimentation with animation techniques was shaped by wartime constraints of time, costs and the new practical considerations of working during air raids. ${ }^{28}$ His graphic, mechanical style of animation was adopted as a medium for both visual education and propaganda, proving valuable in a number of different forms for the MoI.

Three of the SFU's early five-minute films - War in the East (1941), Middle East (1942), and Naval Operations (1941) - used animated maps to explain different aspects of the war effort. A simple diagrammatic style - using arrows and symbols to indicate trade routes and raw materials, battleships and trajectories, and national relationships - emphasises the educational 
or informational role of these films, distinguishing them from other five-minuters using dramas and cartoons to enliven propaganda messages. An austere style of information design is particularly evident in War in the East. Interwoven with animated maps, a man moves labels on printed maps to show the movement of Allied forces in the Middle East; compasses are used to draw a pencil line around Singapore to show the line of British defence; and a hand reaches in to the frame and pulls down string lines to visually illustrate the Allies' stop to supplies. The analysis of War in the East in Mass-Observation's 1942 report concludes that 'the informative film [...] aims to impart facts' and 'is more likely [.... to succeed in its job than the more "propagandist" film'. ${ }^{29}$ Shell's emphasis on 'imparting the facts' in the map films is characterised by a symbolic system that reinforces their nationalistic propaganda function. For instance, in War in the East, dark colouring and black arrows are used to portray Japan as aggressive and threatening and, in Middle East, this propagandistic symbolism is taken further with graphic symbols for Axis soldiers with guns at the ready flashing over a map of the Middle East and casting looming shadows over a brightly lit white space indicative of the Allied 'stronghold'. 30

Further demonstrating their educational focus, many of Rodker's animated sequences were made for training films distributed using the Ministry's non-theatrical circuits. Initially headed by the documentary movement's distribution expert, Thomas Baird, the MoI's network for non-theatrical distribution served as an avenue for 'background' propaganda in the form of film education. ${ }^{31}$ As such, a number of Shell's educational films were released as part of the general programmes shown to audiences in village halls and social clubs. For instance, Airscrew (1940) - which explains the production of aeroplane propellers using diagrammatic sequences combining basic line diagrams with more sophisticated, realist illustrations and models - was included in general programmes on 'Men and Armaments' ${ }^{32}$ 
Animated sequences were also used as illustrative asides in training films targeted at specialised groups, often alongside live-action scenes. For example, Debris Tunnelling (1943) details processes for digging through rubble through a combination of live action shots of a group of wardens with line diagrams, smudged with charcoal and accompanied by hand-written labels, to show the structures needed to do so. Similar combinations were used in SFU films for the National Fire Service, including more formal black and white line and letter diagrams to show the NFS chain of command in Mobilising Procedure (1942), and the same style to depict the calculations for getting water to bomb damaged sites in Model Procedure for Water Relaying (1942).

The integration of Rodker's animated sequences is particularly inventive in Control Room (1942), a film made for the Civil Defence Service in order to explain the chain of communication activated in the event of an air raid. Control Room uses a system of bold graphic symbols to denote the different stations and officers involved in this emergency system. A shot of a chain linking these stations is first introduced as a 'simple plan' of communications, which over the course of the film is illustrated by live action sequences depicting the different sections of the Civil Defence Service in Bristol, accompanied by complementary diagrams to explain their role as part of the system as a whole. Using sound bridges, transitions including wipes and fades, and visual congruences between live action scenes and animated sections, the diagrams are closely interwoven into the action of the documentary-style sequences - serving as the film's 'connective tissue'. ${ }^{33}$

Rodker himself emphasised that animated diagrams - carefully planned to be entertaining and closely integrated into the rest of the film - would ensure effective education. In a piece on the 'Diagram Sequence' published in the Documentary News Letter in 1941, Rodker draws 
attention to the change of medium when a diagram comes up on the screen and 'the subconscious schoolroom feeling we get $[\ldots]$ reminiscent of school, where uninteresting drawings were chalked up on blackboards, and textbook illustrations were devoid of interest and life'. ${ }^{34}$ He suggests that this feeling could be avoided by 'weaving diagrams into actuality in such a way as to make the audience unconscious of the change of medium, thus retaining uninterrupted attention': for example, by depicting the live-action and diagrams from a similar angle. Rodker's technique of creating visual congruence between diagrammatic sequences and others is evident in a number of his SFU films: in Control Room, a shot of a warden in her ' $\mathrm{W}$ ' helmet fades to a graphic symbol depicting the warden's office with a large W emblazoned on a helmet; in Debris Tunnelling, a shot of the wooden tunnel structure being built on a bombsite fades to a hand-drawn diagram of the different parts of the same wooden structure from the same angle, visually connecting the real clearance of rubble in practice (highlighted by the realist, documentary style used) with the theory and planning behind it.

Rodker's educational animations were not simply used to explain ideas and processes, but simultaneously served as visual systems for propaganda. Rodker's animated diagrams, a communications network themselves, were used to convey the strength and efficiency of British wartime networks: from the calculations behind anti-aircraft guns in Ack-Ack to the organisation of sea battles in Naval Operations; from hose pipe routes and measurements in Model Procedure for Water Relaying to the civil defence communications network in Control Room. The starkness of his diagrams, while simple and educational in purpose, was also developed as a realistic interpretation of information that was closely in tune with the realities of their subjects. The smooth visual integration of diagrams into the depiction of communications networks illuminated in Control Room - and the proximity between visual 
representation through animation and wartime life - is particularly dramatic. In a sequence depicting the destruction of the central control room in the network, civil defence workers are shown crawling out from rubble and fallen rafters, followed by an iris shot which reveals the animated diagram of the emergency communications system. The damaged control room remains at the centre of the diagram until it becomes a dull black scorch mark on the diagram itself, replacing a symbol formerly denoting the control room. Accompanied by the ominous sound of an aeroplane overhead (and the dramatic silence of the control centre's communications), the sections of the diagram immediately surrounding the scorch mark start to blur and the lines connecting different sections of the network become duller to visually convey a loss of communications. The diagram of the civil defence communications network is visibly damaged, seemingly as a result of bombing. The animated diagrams are therefore deployed as a visually symbolic system representative of the communications network explained throughout the film: the diagrams are carefully integrated into the film's action with the aim of maintaining the audience's attention and fulfilling the Control Room's educational function.

\section{'A Very Flexible Medium of Propaganda'}

From Disneyesque marching vegetables to black and white diagrams charting hose pipe measurements, the animation styles of Halas and Batchelor and Francis Rodker were visually very different. In an interview with Kay Mander in 1972, Joy Batchelor said that they didn't come into contact at all, and Halas' co-authored 1959 book on animation technique drew attention to Rodker's 'specialized technical animation' as a 'radically different method' from others detailed. ${ }^{35}$ Jez Stewart has noted Halas' publicly dismissive attitude towards his advertising work and Halas' published writing emphasises a clear distinction between animation for advertising films in theatres and for public relations, propaganda, instructional 
and educational films. ${ }^{36}$ However, the animated films made for the MoI by both studios offer a more nuanced picture of the relationship between advertising and animation in wartime.

The MoI films made throughout the war indicate the studios' creative blurring of such distinctions - in terms of style, format and distribution - in an effort to use animation as a 'flexible medium of propaganda'. Influenced by aesthetic styles and modes of distribution developed for the purposes of film advertising in their respective fields, both studios developed mutable modes of address in films distributed via cinemas and non-theatrical circuits: creating narratives and offers of transformation; incorporating documentary influences and providing specialised information; and combining entertainment with education in different permutations and with different aims. As such, the studios' distinctive animation styles developed according to the fluctuating needs of wartime propaganda and, in doing so, advanced a flexible system for visual communication.

Many thanks to the staff at the Imperial War Museum Film archive for all their help with accessing some of the films consulted and to Colin Burgess for his advice and assistance on the Shell Film Unit.

\section{Bibliography}

Aldgate, Anthony, and Jeffrey Richards. 2007. Britain Can Take It: British Cinema in the Second World War. First Pub. 1986. London: I. B. Tauris.

Burgess, Colin. 2010. Sixty Years of Shell Film Sponsorship, 1934-94. Journal of British Cinema and Television 7. 2:213-31. doi: 10.3366/jbctv.2010.0003.

Chapman, James. 2000. The British at War: Cinema, State and Propaganda, 1939-1945. First Pub. 1998. London: I. B. Tauris.

Halas, John, and Roger Manvell. 1959. The Technique of Film Animation. London: Focal Press.

Richards, Jeffrey, and Dorothy Sheridan. 1987. Mass-Observation at the Movies. London: Routledge.

Roe, Annabelle Honess. 2017. Interjections and Connections: The Critical Potential of Animated Segments in Live Action Documentary. Animation: an interdisciplinary journal 12.3:272-86. Doi: $10.1177 / 1746847717729552$.

Stewart, Jez. 2016. Robin Hood and the Furry Bowlers: Animators Vs. Advertisers in Early British Television Commercials. In Films That Sell: Moving Pictures and Advertising, ed. Bo Florin, Nico De Klerk and Patrick Vonderau, 239-50. London: Palgrave Macmillan, on behalf of the BFI.

Vigars, Norman. 1984. History of the Shell Film Unit: 50th Anniversary.

Wells, Paul. 1997. The Beautiful Village and the True Village: A Consideration of Animation and the Documentary Aesthetic. Art and Animation 12. 3/4 March-April: 40-45. 1995. Dustbins, Democracy and Defence: Halas and Batchelor and the Animated Film in Britain 19401947. In War Culture: Social Change and Changing Experience in World War Two, ed. Pat Kirkham and David Thoms, 61-72. London: Lawrence \& Wishart Ltd. 2014. Joy, Britain Needs You. In A Moving Image: Joy Batchelor 1914-1991, Artist, Writer and Animator, 59-79. London: Southbank Publishing. 


\footnotetext{
${ }^{1}$ Documentary News Letter, April 1942, 55.

${ }^{2}$ Documentary News Letter, 55.

${ }^{3}$ The chapter relies on records of the Films Division's work held at the National Archives in Kew, UK (TNA) and in the Sidney Bernstein collection at the Imperial War Museum (IWM), as well as contemporary publications, reports and interviews with the animators in question.
}

${ }^{4}$ TNA INF 1.867 Ministry of Information - Co-Ordinating Committee Minutes and Papers, Programme for Film Propaganda, October 1939-April 1940.

${ }^{5}$ TNA INF 1.867 Ministry of Information - Co-Ordinating Committee Minutes and Papers. In 1940, when the MoI sent a film expert to the US to report on the possibilities for film propaganda targetting US audiences, liaising with Walt Disney was a high priority. At the same time, Disney characters were discussed elsewhere at the Ministry as a potentially valuable 'medium' of 'world wide appeal' (TNA INF 1.536 Export publicity scheme: utilising the Disney characters).

${ }^{6}$ TNA INF 1.867 Ministry of Information - Co-Ordinating Committee Minutes and Papers.

${ }^{7}$ Anthony Aldgate and Jeffrey Richards, Britain Can Take It: British Cinema in the Second World War (London: I.B. Tauris, First Pub. 1986, 2007), 7.

${ }^{8}$ Advertiser's Weekly: The Organ of British Advertising, 18 April 1940, 74.

${ }^{9}$ TNA INF 1.126 Re-Organisation of Films Division, 1940-46.

${ }^{10}$ See Charles Drazin, The Finest Years: British Cinema of the 1940s (London: I. B. Tauris, First Pub. 1997, 2007), 177-85 and Ruth Artmonsky, Jack Beddington: The Footnote Man (London: Artmonsky Arts, 2006).

${ }^{11}$ Kenneth Clark quoted in Jeffrey Richards and Dorothy Sheridan, Mass-Observation at the Movies (London: Routledge, 1987), 424. On the five-minute film scheme and its reception, see: James Chapman, The British at War: Cinema, State and Propaganda, 1939-1945 (London: I. B. Tauris, First Published 1998, 2000), 86-113. ${ }^{12}$ IWM 65.17.2 Sidney Bernstein Collection. Letter from Paul Rotha - Notes on M. Of I. 5-Minute Films, 18 August 1940.

${ }^{13}$ Paul Wells, "Dustbins, Democracy and Defence: Halas and Batchelor and the Animated Film in Britain 19401947," in War Culture: Social Change and Changing Experience in World War Two, ed. Pat Kirkham and David Thoms (London: Lawrence \& Wishart Ltd., 1995), 64-5. This stress on entertainment in animated advertising films in cinemas is noted in Jez Stewart, "Robin Hood and the Furry Bowlers: Animators Vs. Advertisers in Early British Television Commercials" in Films That Sell: Moving Pictures and Advertising, ed. Bo Florin, Nico De Klerk and Patrick Vonderau (London: Palgrave Macmillan, on behalf of the BFI, 2016), 245.

${ }^{14}$ John Halas and Roger Manvell, The Technique of Film Animation (London: Focal Press, 1959), 114.

15 Halas andManvell, 115. This technique was developed in the studio's later commercial advertising work, as examined in Paul Wells, "Joy, Britain Needs You," in A Moving Image: Joy Batchelor 1914-1991, Artist, Writer and Animator (London: Southbank Publishing, 2014), 69.

${ }^{16}$ Wells, 63-66.

${ }^{17}$ For further discussion of the role of fairy tales as a model for advertising, see Tashi Petter's analysis in chapter 3)

18 Wells, 66-67.

${ }^{19}$ Wells, 66-67.

20 "M-O File report 1193 'Report on Ministry of Information Shorts, 1 April 1942'," in Jeffrey Richards and Dorothy Sheridan, Mass-Observation at the Movies (London: Routledge, 1987), 455.

${ }^{21}$ John Halas referenced in Paul Wells, "The Beautiful Village and the True Village: A Consideration of Animation and the Documentary Aesthetic", Art and Animation 12. 3/4 March-April, 41.

${ }^{22}$ John Halas and Joy Batchelor, "European Cartoon", The Penguin Film Review (1949), 15.

${ }^{23}$ Documentary News Letter, April 1942, 55.

${ }^{24}$ Documentary News Letter, 55.

${ }^{25}$ Norman Vigars, History of the Shell Film Unit: 50th Anniversary (1984), x.

${ }^{26}$ Grierson's memorandum on SFU production (1937) quoted in: Norman Vigars, History of the Shell Film Unit: 50th Anniversary (1984), ix.

${ }^{27}$ Francis Rodker, Transcript of an Interview Recorded in April, Shell International Archive, London (1983), 14.

For context, see: Colin Burgess, "Sixty Years of Shell Film Sponsorship, 1934-94", Journal of British Cinema and Television 7.2 (2010), 215-18.

${ }^{28}$ Rodker, 20-1.

29 “M-O File report 1193 'Report on Ministry of Information Shorts, 1 April 1942'," in Jeffrey Richards and Dorothy Sheridan, Mass-Observation at the Movies (London: Routledge, 1987), 451. 


\footnotetext{
${ }^{30}$ This is a graphic language shared with the Why We Fight series, as examined in Annabelle Honess Roe, "Interjections and Connections: The Critical Potential of Animated Segments in Live Action Documentary", Animation: an interdisciplinary journal 12.3 (2017), 274.

${ }^{31}$ Documentary News Letter, September 1941, 170. IWM 65.17.4 Sidney Bernstein Collection. Memorandum on British Non-Theatrical Film Distribution, 1 April 1940.

${ }^{32}$ IWM 65.17.4 Sidney Bernstein Collection. British Non-Theatrical Film Distribution Scheme - Progress Report, November 1940.

${ }^{33}$ Annabelle Honess Roe, 273, 282.

${ }^{34}$ Francis Rodker, Documentary News Letter, July 1941, 138.

${ }^{35}$ Joy Batchelor, BECTU History Project - Interview No.294, Transcript of Interview in May 1972.

Halas and Manvell, 234.

${ }^{36}$ Jez Stewart, "Robin Hood and the Furry Bowlers: Animators Vs. Advertisers in Early British Television Commercials" in Films That Sell: Moving Pictures and Advertising, ed. Bo Florin, Nico De Klerk and Patrick Vonderau (London: Palgrave Macmillan, on behalf of the BFI, 2016), 246-47; John Halas and Roger Manvell, The Technique of Film Animation (London: Focal Press, 1959), 107-148.
} 